Check for updates

Cite this: RSC Adv., 2019, 9, 14060

\title{
Heterogeneous activation of peroxymonosulfate for bisphenol AF degradation with $\mathrm{BiOl}_{0.5} \mathrm{Cl}_{0.5} \dagger$
}

\author{
Weihong Tang, ${ }^{a}$ Yongli Zhang, (D) *a Hongguang Guo ab and Yang Liu ${ }^{a}$
}

This study represents the first investigation on the application of peroxymonosulfate (PMS) for the degradation of bisphenol AF (BPAF) using halogen bismuth oxide composites $\left(\mathrm{BiOl}_{0.5} \mathrm{Cl}_{0.5}\right)$. The hierarchical $\mathrm{BiOl}_{0.5} \mathrm{Cl}_{0.5}$ was successfully synthesized and systematically characterized with multifarious techniques including XRD, SEM, FTIR and XPS to investigate the morphology and physicochemical properties of the samples. Several parameters affecting the degradation efficiency including catalyst dosage, PMS loading, and $\mathrm{pH}$ value were elucidated. Inorganic ions such as $\mathrm{HCO}_{3}{ }^{-}$showed significant inhibition in the $\mathrm{BiOl}_{0.5} \mathrm{Cl}_{0.5} / \mathrm{PMS}$ process due to the quenching effect. The effect of various water matrices including tap water and surface water on the removal of BPAF was studied to indicate that the present reaction system shows great potential for cleaning BPAF waste water. Furthermore, the production of sulfate radicals and hydroxyl radicals was validated through radical quenching and ESR tests, thus a possible oxidation mechanism was proposed. Overall, these results reveal that the activation of PMS by the $\mathrm{BiOl}_{0.5} \mathrm{Cl}_{0.5}$ /PMS system is an efficient and promising advanced oxidation technology for the treatment of BPAF-contaminated waters and wastewaters.

Received 6th March 2019 Accepted 20th April 2019

DOI: 10.1039/c9ra01687b

rsc.li/rsc-advances in the present study, BPAF was chosen as the target for degradation and removal.

Recently, advanced oxidation processes (AOPs) based on persulfate (PS) or peroxymonosulfate (PMS) have been attracted great attention. It has been confirmed that sulfate radicals $\left(\cdot \mathrm{SO}^{4-\bullet}\right)$ provide an effective way for removing reluctant organic compounds in the water, ${ }^{\mathbf{1 8 , 1 9}}$ due to the following reasons: (1) $\cdot \mathrm{SO}^{4-\cdot}$ possesses a longer half-life than $\mathrm{OH}^{*} ;(2) \cdot \mathrm{SO}^{4-\cdot}$ radicals $\left(E_{0}=2.5-3.1 \mathrm{~V}\right)$ exhibit higher oxidation potentials than $\mathrm{OH}^{*}$ radicals $\left(E_{0}=1.8-2.7 \mathrm{~V}\right)$ and $(3) \cdot \mathrm{SO}^{4-\cdot}$ radicals are more selective towards destruction of aromatic molecules. ${ }^{2021}$ In recent years, lots of researchers have focused their attention on the oxone (potassium peroxymonosulfate, PMS), which is an eco-friendly and promising source to generate $\cdot \mathrm{SO}^{4-}$. radicals. ${ }^{22-27}$

On the other hand, bismuth oxyhalides (BiOX, $\mathrm{X}=\mathrm{Cl}, \mathrm{Br}$ and I) have been admitted as excellent adsorbents and photocatalysts for the removal of organic pollutants in the water. ${ }^{28-31}$ The band gaps of BiOX can be within 1.7-3.4 eV by varying the halides and the composition ratios of the two halides $\left(\mathrm{BiOX}_{\alpha^{-}}\right.$ $\left.\mathrm{Y}_{1-\alpha}\right) .^{32}$ Owing to the high separation rate of photo-induced electron-hole pairs, the past ten years have witnessed tremendous efforts in utilizing BiOCl as a promising catalyst for photocatalytic applications under visible light irradiation, including pollutants removal, $\mathrm{N}_{2}$ fixation, $\mathrm{CO}_{2}$ reduction and water splitting..$^{33}$ However, most of the photocatalytic oxidation reaction based on BiOX usually needs several hours or more for pollutant removal. Therefore, it is necessary to promote technology combined with another antioxidant. To our best
${ }^{a}$ College of Architecture and Environment, Sichuan University, Chengdu 610065, China. E-mail: xyl_scu@126.com; Fax: +86-028-85405534; Tel: +86-028-85408889 ${ }^{b}$ Department of Civil \& Environmental Engineering, University of Washington, Box 352700, Seattle, WA 98195-2700, USA

$\dagger$ Electronic supplementary information (ESI) available. See DOI: $10.1039 / \mathrm{c} 9 \mathrm{ra} 01687 \mathrm{~b}$ 
knowledge, bismuth oxyhalide has not been tested as an activator of peroxide for water purification. There is a handful of research has been reported that the interaction between the PMS and BiOX for organic wastewater treatment. ${ }^{34}$

Hence, in the present study, we represent the first investigation on the potential application of $\mathrm{BiOI}_{0.5} \mathrm{Cl}_{0.5}$ combined with PMS. We synthesized hierarchical $\mathrm{BiOI}_{0.5} \mathrm{Cl}_{0.5}$ using the solvothermal method. BPAF, which is commonly used in the chemical and textile industries were selected as typical targets. Multiple characterizations including XRD, SEM, FTIR, XPS and ESR were applied to evaluate the physicochemical performance of $\mathrm{BiOI}_{0.5} \mathrm{Cl}_{0.5}$ and reaction mechanism. In addition, several key parameters including catalyst dosage, PMS loading, the initial $\mathrm{pH}$ of BPAF solution and common anions were investigated. Besides, the realistic conditions were also investigated for the system using tap water and surface water conditions. Finally, a possible reaction mechanism was proposed based on the scavenger experiments.

\section{Materials and methods}

\subsection{Materials and reagents}

$\mathrm{Bi}\left(\mathrm{NO}_{3}\right)_{3} \cdot 5 \mathrm{H}_{2} \mathrm{O}$, $\mathrm{KI}$ and $\mathrm{KCl}$ were purchased from Kelong Chemical Reagent Co. (Chengdu, China). Bisphenol AF (BPAF) was purchased from Sigma-Aldrich Co., Ltd (Shanghai, China). Peroxymonosulfate (PMS) was obtained from Aladdin China. All other chemical reagents were analytical grade and used without further purification. The typical solutions used were prepared using Milli-Q water system (18.2 $\left.\mathrm{M} \Omega \mathrm{cm}^{-1}\right)$.

\subsection{Synthesis of composites bismuth oxyhalides}

The three catalysts were synthesized as the modified procedure reported by previous studies: ${ }^{29} 8.731 \mathrm{~g} \mathrm{Bi}\left(\mathrm{NO}_{3}\right)_{3} \cdot 5 \mathrm{H}_{2} \mathrm{O}$ was dissolved in $180 \mathrm{~mL}$ ethylene glycol under intense stirring for $30 \mathrm{~min}$ to obtain solution A. Then, $2.989 \mathrm{~g} \mathrm{KI}$ (for BiOI), $1.344 \mathrm{~g}$ $\mathrm{KCl}$ (for $\mathrm{BiOCl}$ ) or $1.494 \mathrm{~g} \mathrm{KI} / 0.672 \mathrm{~g} \mathrm{KCl}$ (for $\mathrm{BiOI}_{0.5} \mathrm{Cl}_{0.5}$ ) was dissolved in $180 \mathrm{~mL}$ water to obtain solution $\mathrm{B}$, respectively. Afterwards, the solution $\mathrm{B}$ was added rapidly into the solution $\mathrm{A}$ under intense stirring for $2 \mathrm{~h}$ at the ambient temperature. The obtained mixture was calcined at $180{ }^{\circ} \mathrm{C}$ for $24 \mathrm{~h}$ in a stainlesssteel autoclave equipped with a Teflon lining. Finally, the mixture was separated and washed three times respectively with ethanol and water, then dried at $60{ }^{\circ} \mathrm{C}$ in vacuum drying oven until use.

\subsection{Experimental procedure}

All experiments were carried out in a borosilicate glass beaker of $500 \mathrm{~mL}$ capacity at ambient temperature $\left(25{ }^{\circ} \mathrm{C} \pm 1{ }^{\circ} \mathrm{C}\right)$. A $200 \mathrm{~mL}$ reaction solution was prepared of BPAF solution at concentration of $10 \mathrm{mg} \mathrm{L}{ }^{-1}$ without $\mathrm{pH}$ adjustment or with adjusting initial $\mathrm{pH}$ using $0.1 \mathrm{~mol} \mathrm{~L}^{-1} \mathrm{HCl}$ and $\mathrm{NaOH}$ solution. In each test, a set of prepared $\mathrm{BiOI}_{0.5} \mathrm{Cl}_{0.5}$ was dispersed in the solution, all the suspensions were magnetically stirred for 10 min in the dark before adding a certain amount of PMS, in order to attain the adsorption-desorption equilibrium between the $\mathrm{BiOI}_{0.5} \mathrm{Cl}_{0.5}$ and the BPAF molecules. At given time intervals, aliquots of the suspension (about $1.5 \mathrm{~mL}$ ) were sampled, filtered by a $0.22 \mu \mathrm{m}$ filter before the concentration detection, quenched immediately by adding $60 \mu \mathrm{L} 0.5 \mathrm{~mol} \mathrm{~L}^{-1} \mathrm{Na}_{2} \mathrm{~S}_{2} \mathrm{O}_{3}$ solution into the $2 \mathrm{~mL}$ auto sampler vials, its volume for PMS quench was $100: 1$. Before the time of zero, a pre-adsorption process for BPAF removal was accomplished.

The concentration of BPAF $(\lambda=270 \mathrm{~nm})$ was detected by a Water e2695 HPLC equipped with UV-visible detection (Waters 2489) at the column temperature of $35{ }^{\circ} \mathrm{C}$. And the mobile phase was maintained at a flow rate of $1.0 \mathrm{~mL} \mathrm{~min}{ }^{-1}$ with a constant ratio (methanol/0.1\% ammonium acetate $=70$ / 30). The total organic carbon (TOC) of samples were measured by an Elementar liquid TOC II analyzer.

The degradation BPAF process approximately followed pseudo-first-order kinetics by data fitting, thus overall rate law for the BPAF degradation can be expressed as eqn (1):

$$
-\ln \left(\frac{C_{t}}{C_{0}}\right)=K_{\text {app }} t
$$

where the $C_{0}$ is initial concentration of BPAF, $C_{t}$ is the concentration of BPAF at time $t$, and $K_{\text {app }}\left(\mathrm{min}^{-1}\right)$ is the observed reaction rate constant.

\subsection{Characterization and analytical procedures}

To determine the morphology of the as-prepared samples, scanning electron microscopy (SEM) measurements were run using a JSM-7500F (JEOL, Japan) at $20 \mathrm{kV}$. The crystal structural characterization of $\mathrm{BiOI}_{0.5} \mathrm{Cl}_{0.5}$ was conducted by powder X-ray diffraction spectrometry (XRD) using an Empyrean diffractometer advance instrument between 10 and $80^{\circ}(2 \theta)$ (PANalytical B.V., Holland). Fourier Transform Infrared Spectrometer (FTIR) results were conducted using a Nicolet 6700 FTIR spectrometer (Thermo Scientific, United States), at the range of 400 to $4000 \mathrm{~cm}^{-1}$ wave numbers. The elemental composites and chemical states of $\mathrm{BiOI}_{0.5} \mathrm{Cl}_{0.5}$ were further elucidated with X-ray photoelectron spectroscopy (XPS) using a XSAM800 (Kratos, UK).

\section{Results and discussion}

\subsection{Characterization of the synthesized samples}

XRD was applied to characterize the chemical composition and crystalline structure of the synthesized $\mathrm{BiOI}_{0.5} \mathrm{Cl}_{0.5}$, the patterns of the samples are presented in Fig. 1. It is clearly that BiOX can be indexed to tetragonal phase structure BiOI (JCPDS card no. 73-2062, the cell parameters of $a=3.984 \AA$ ) and BiOCl (JCPDS card no. 73-2060, the cell parameters of $a=3.883 \AA$ ), indicating a high purity of the products. Moreover, the XRD peaks of the $\mathrm{BiOI}_{0.5} \mathrm{Cl}_{0.5}$ sample is weaker and broader than the pure BiOI and BiOCl, demonstrating a smaller particle size and lower crystallinity to some extent. ${ }^{35}$ The major peaks are positioned at $2 \theta=11.1^{\circ}, 25.8^{\circ}, 29.9^{\circ}, 32.0^{\circ}$ and $32.6^{\circ}$. The shift of (001), (101), (102) and (110) planes are the strong evidence to determine the intercalated layer products, indicating that the as-prepared $\mathrm{BiOI}_{0.5} \mathrm{Cl}_{0.5}$ composite is not merely a mixture of $\mathrm{BiOI}$ and BiOCl. $^{36}$ 


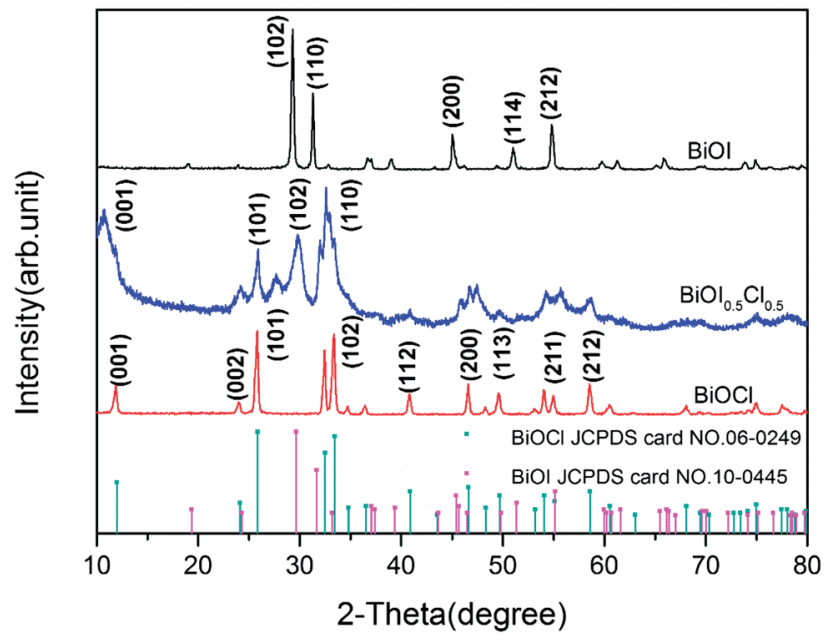

Fig. 1 XRD patterns of $\mathrm{BiOl}, \mathrm{BiOCl}$ and $\mathrm{BiOl}_{0.5} \mathrm{Cl}_{0.5}$.

The low- and high-magnification SEM images of synthesized $\mathrm{BiOI}_{0.5} \mathrm{Cl}_{0.5}$ are presented in Fig. 2. Obviously, the prepared $\mathrm{BiOI}_{0.5} \mathrm{Cl}_{0.5}$ samples are dominated with the hierarchical nanoplates. ${ }^{36}$ The nanoplate like structure of the catalysts is mainly seems to consists of quite uniform plates with width of about $100 \mathrm{~nm}$ and thickness of about $20 \mathrm{~nm}$, these observations are in accordance with the reported literature. ${ }^{37}$ The formation of 2-dimension nanoplates structure can be ascribed to the internal structure of $\mathrm{BiOI}_{0.5} \mathrm{Cl}_{0.5}$, where $\left[\mathrm{Bi}_{2} \mathrm{O}_{2}\right]^{2+}$ layers are interleaved by two slabs of $\mathrm{X}^{-\cdot}$ atoms, leading to the anisotropic growth at certain axis. ${ }^{38}$ In addition, the element mapping clearly illustrates the homogeneous distribution of $\mathrm{O}, \mathrm{Bi}, \mathrm{I}$ and $\mathrm{Cl}$ species in the prepared $\mathrm{BiOI}_{0.5} \mathrm{Cl}_{0.5}$ samples composite (as shown in Fig. S1†).

FT-IR spectra was applied to investigate and compare the functional groups on BiOI, BiOCl and $\mathrm{BiOI}_{0.5} \mathrm{Cl}_{0.5}$. As shown in Fig. 3, characteristic absorption peaks at 528, 1375 and $1650 \mathrm{~cm}^{-1}$ are observed in BiOI. The peak at $528 \mathrm{~cm}^{-1}$ is associated with the $\mathrm{Bi}-\mathrm{O}$ stretching mode, while the absorption peaks at $1375 \mathrm{~cm}^{-1}$ could be assigned as the asymmetry and symmetric stretching vibration peaks for Bi-I band. ${ }^{39}$ Similar

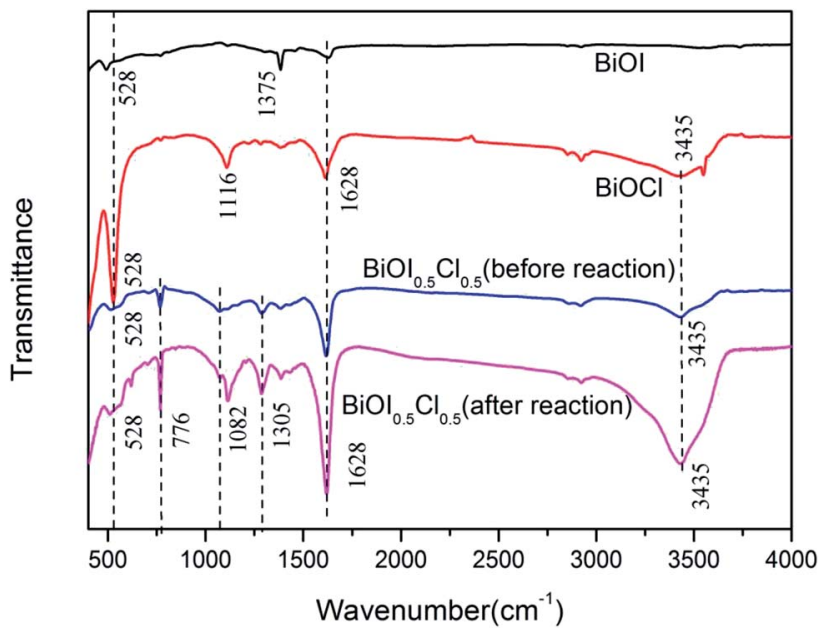

Fig. 3 FTIR spectra of the synthesized $\mathrm{BiOl}_{0.5} \mathrm{Cl}_{0.5}, \mathrm{BiOl}$ and $\mathrm{BiOCl}$.

characteristic peaks emerge at $1116 \mathrm{~cm}^{-1}$ for $\mathrm{Bi}-\mathrm{Cl}$ band in BiOCl structure. The band at $3435 \mathrm{~cm}^{-1}$ and $1628 \mathrm{~cm}^{-1}$ for $\mathrm{BiOI}_{0.5} \mathrm{Cl}_{0.5}$, BiOCl and BiOI are the stretching of $\mathrm{O}-\mathrm{H}$ and flexural vibrations of $\mathrm{O}-\mathrm{H}$ in the free water. ${ }^{40}$ No characteristic adsorption peaks of the ionic liquid are found in the FT-IR spectra, indicating that the ionic liquid can be easily removed from the surface of the synthesized $\mathrm{BiOI}_{0.5} \mathrm{Cl}_{0.5}$ by washing with alcohol and water. Besides, significant changes are observed between the fresh and used $\mathrm{BiOI}_{0.5} \mathrm{Cl}_{0.5}$ at $776 \mathrm{~cm}^{-1}, 1082 \mathrm{~cm}^{-1}$ and $1305 \mathrm{~cm}^{-1}$ illustrated in Fig. 3, which might be formed by the adsorption of BPAF degradation products and other radicals. The peak at $1082 \mathrm{~cm}^{-1}$ corresponded to $\mathrm{C}-\mathrm{O}-\mathrm{C}$ stretching vibration, ${ }^{41}$ and the respective shift in $776 \mathrm{~cm}^{-1}$ and $1305 \mathrm{~cm}^{-1}$ peaks confirmed the interaction among $\mathrm{BiOI}_{0.5} \mathrm{Cl}_{0.5}$, PMS and BPAF, indicating that the degradation process takes place on the surface of the $\mathrm{BiOI}_{0.5} \mathrm{Cl}_{0.5}$.

XPS spectra is considered as an effective analysis to obtain further insight into the elemental composition and chemical states of the prepared samples. As shown in the Fig. 4(a), the coexistence of $\mathrm{Bi} 4 \mathrm{f}, \mathrm{I} 3 \mathrm{~d}, \mathrm{Cl} 2 \mathrm{p}$ and $\mathrm{O} 1 \mathrm{~s}$ peaks indicated the catalysts consisted of $\mathrm{Bi}, \mathrm{I}, \mathrm{Cl}$ and $\mathrm{O}$ elements. The carbon peak

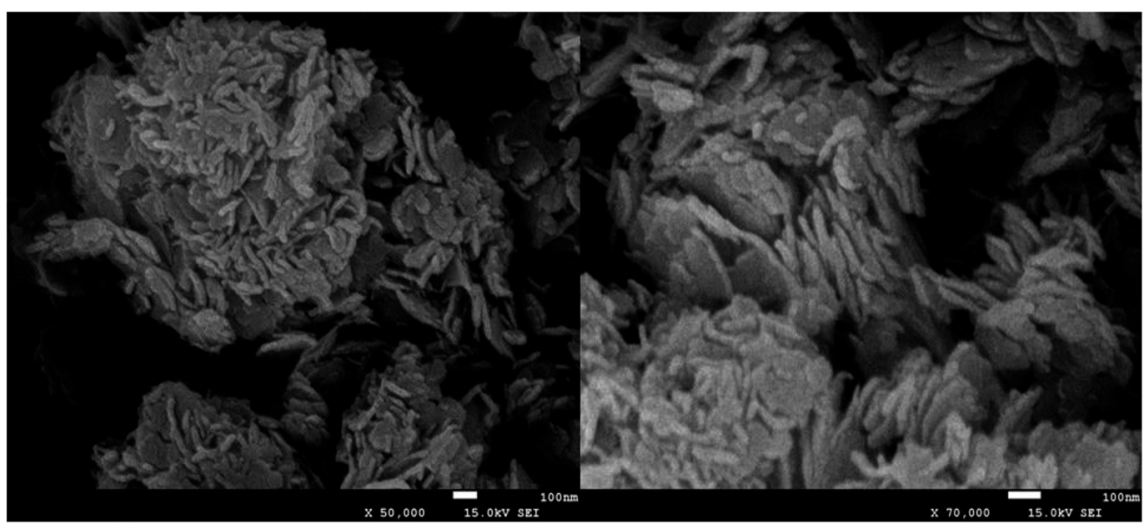

Fig. 2 SEM images of synthesized $\mathrm{BiOl}_{0.5} \mathrm{Cl}_{0.5}$. 

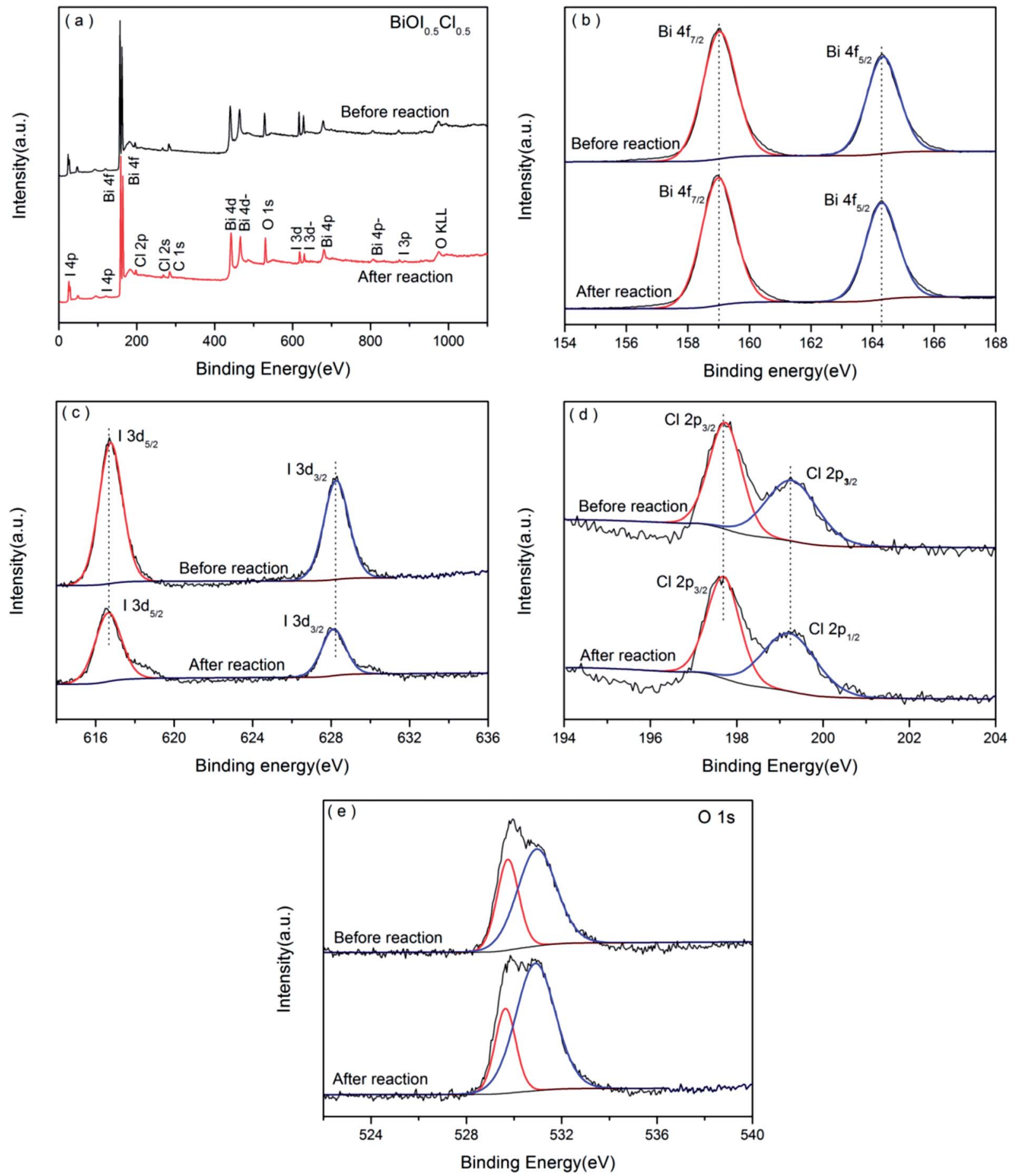

Fig. 4 XPS spectra of catalyst before and after reaction: (a) a typical XPS survey spectrum, and high-resolution XPS of (b) Bi 4f, (c) I 3d, (d) Cl 2p and (e) $\bigcirc 1 \mathrm{~s}$.

resulted from the adventitious carbon from atmosphere, which was used to correct the shift of the binding energy at $284.6 \mathrm{eV} .^{42}$ There are two strong peaks at $158.9 \mathrm{eV}$ and $164.3 \mathrm{eV}$ (illustrated in Fig. 4(b)) contributing to $\mathrm{Bi} 4 \mathrm{f}_{7 / 2}$ and $\mathrm{Bi} 4 \mathrm{f}_{5 / 2}$, which demonstrates the presence of Bi-O bonding with trivalent oxidation state. ${ }^{43}$ Fig. $4(\mathrm{c})$ shows that the centered peaks at $617.8 \mathrm{eV}$ and $629.4 \mathrm{eV}$ were well corresponded to the inner electron of I $3 d_{5 / 2}$ and I $3 d_{3 / 2}$, respectively. The binding energies of $197.7 \mathrm{eV}$ and $199.3 \mathrm{eV}$ associated with $\mathrm{Cl} 2 \mathrm{p}_{3 / 2}$ and $\mathrm{Cl} 2 \mathrm{p}_{1 / 2}$ (illustrated in Fig. 4(d)), which showed the existence of $\mathrm{Cl}^{-}$in $\mathrm{BiOI}_{0.5} \mathrm{Cl}_{0.5}{ }^{44}$ The $\mathrm{O}$ 1s peaks can be deconvoluted into two bands at 529.7 and $531.0 \mathrm{eV}$ (illustrated in Fig. 4(e)), assigned to $\mathrm{Bi}-\mathrm{O}$ and $\mathrm{I}-\mathrm{O}$ bands ${ }^{45,46}$ What's more, the peaks of $\mathrm{O} 1 \mathrm{~s}$ change to higher binding energy value and I $3 \mathrm{~d}$ change to lower binding 
energy in the catalyst after reaction, suggesting that the degradation process takes place on the surface of the $\mathrm{BiOI}_{0.5} \mathrm{Cl}_{0.5} \cdot{ }^{47}$

\subsection{Degradation efficiency of $\mathrm{BPAF}$ in $\mathrm{PMS} / \mathrm{BiOI}_{0.5} \mathrm{Cl}_{0.5}$ process}

The synthesized $\mathrm{BiOI}_{0.5} \mathrm{Cl}_{0.5}$ was employed at a dosage of $0.5 \mathrm{~g}$ $\mathrm{L}^{-1}$. The removal of BPAF by single PMS, single $\mathrm{BiOI}_{0.5} \mathrm{Cl}_{0.5}$ or $\mathrm{PMS} / \mathrm{BiOI}_{0.5} \mathrm{Cl}_{0.5}$ is shown in Fig. 5. The $\mathrm{pH}$ of the initial solutions was about $7.50 \pm 0.05$. As can be seen, in the absence of $\mathrm{BiOI}_{0.5} \mathrm{Cl}_{0.5}$, the degradation of BPAF by PMS was negligible within investigated time scale. Comparatively, the adsorption by single $\mathrm{BiOI}_{0.5} \mathrm{Cl}_{0.5}$ contributed $27.3 \%$ removal of BPAF. It can be seen that the adsorption capacity increased quickly in the first $2 \mathrm{~min}$ and then the adsorption equilibrium was reached within $10 \mathrm{~min}$. In contrast, BPAF could be appreciably degraded in $\mathrm{PMS} / \mathrm{BiOI}_{0.5} \mathrm{Cl}_{0.5}$ system with $99.1 \%$ removal rate at $60 \mathrm{~min}$. It was obvious that peroxymonosulfate had a positive influence on the degradation of BPAF, indicating the generation of ROS (reactive oxygen species) via activation of PMS. 43.9\% mineralization was achieved after 60 min reaction, when the nearly complete removal of BPAF was observed, indicating that the significant amounts of reaction by-products were refractory to be oxidized. ${ }^{48}$

Besides, control experiments were carried out to compare the BPAF removal efficiency for various processes at BiOI/PMS and $\mathrm{BiOCl} / \mathrm{PMS}$ processes within $60 \mathrm{~min}$. As shown in Fig. $\mathrm{S} 2, \uparrow$ the synthesized $\mathrm{BiOI}_{0.5} \mathrm{Cl}_{0.5}$ showed the highest activity for activation of PMS to produce sulfate radicals and $99.1 \%$ BPAF removal was achieved within $60 \mathrm{~min}$, while BiOI and BiOCl possessed a lower activity and provided $31.3 \%$ and $48.3 \%$ BPAF removal respectively in the same time. The nitrogen adsorption-desorption test was conducted using the BET method, with the results presented in Fig. S3, $\uparrow$ the inset shows the $\mathrm{BJH}$ pore size distribution for the prepared samples. $\mathrm{BiOI}_{0.5} \mathrm{Cl}_{0.5}$ has a large surface area $\left(44.94 \mathrm{~m}^{2} \mathrm{~g}^{-1}\right)$ and pore volume $\left(0.454 \mathrm{~cm}^{3} \mathrm{~g}^{-1}\right)$, which is larger than that of individual BiOI $\left(2.499 \mathrm{~m}^{2} \mathrm{~g}^{-1}\right)$ or BiOCl $\left(4.992 \mathrm{~m}^{2} \mathrm{~g}^{-1}\right) .{ }^{36}$ From the results

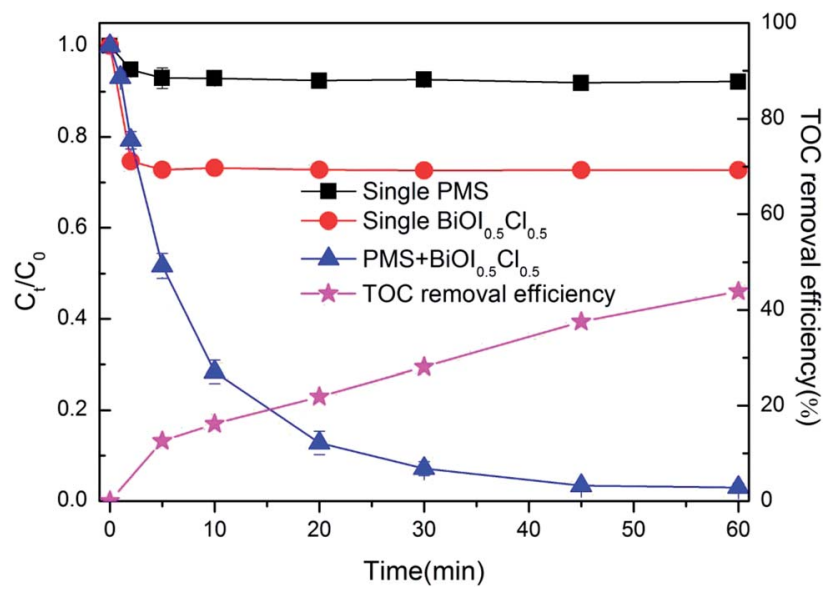

Fig. 5 Removal of BPAF in different reaction systems ([BPAF] $=$ $10 \mathrm{mg} \mathrm{L}^{-1}, \mathrm{PMS} / \mathrm{BPAF}=5 / 1, \mathrm{BiOl}_{0.5} \mathrm{Cl}_{0.5}$ dosage $=0.5 \mathrm{~g} \mathrm{~L}^{-1}, T=298 \mathrm{~K}$, initial $\mathrm{pH}=7.50$ ). of this experiment, we get the conclusion that the structure and surface chemistry of the BiOX would of course be expected to affect its activation of peroxides and thus the overall degradation effectiveness and the synthesized $\mathrm{BiOI}_{0.5} \mathrm{Cl}_{0.5}$ has the superior activation. ${ }^{49}$

In the removal process, both the adsorption of $\mathrm{BiOI}_{0.5} \mathrm{Cl}_{0.5}$ and the oxidation of PMS activated by $\mathrm{BiOI}_{0.5} \mathrm{Cl}_{0.5}$ were simultaneous for BPAF removal. In this work, all the suspensions were magnetically stirred for $10 \mathrm{~min}$ in the dark before adding a certain amount of PMS, in order to attain the adsorptiondesorption equilibrium between the $\mathrm{BiOI}_{0.5} \mathrm{Cl}_{0.5}$ and the BPAF molecules.

\subsection{Effect of reaction parameters}

3.3.1 Effect of catalyst dosages. The influence of different catalyst dosages on the catalytic degradation of BPAF by PMS/ $\mathrm{BiOI}_{0.5} \mathrm{Cl}_{0.5}$ system was performed in $0.1-1.0 \mathrm{~g} \mathrm{~L}^{-1}$ range. Before adding the PMS, the adsorption efficiencies of BPAF by varying the $\mathrm{BiOI}_{0.5} \mathrm{Cl}_{0.5}$ dosage were detected in Fig. $\mathrm{S} 4, \uparrow$ the adsorption capacity all increased quickly in the first $2 \mathrm{~min}$ and then the adsorption equilibrium was reached within $10 \mathrm{~min}$. Besides, with the improvement of catalyst dosage from $0.5 \mathrm{~g} \mathrm{~L}^{-1}$ to $1.0 \mathrm{~g}$ $\mathrm{L}^{-1}$, the adsorption of BPAF just increased about $4.88 \%$.

As shown in Fig. 6(a), the BPAF removal efficiency enhanced from $30.98 \%$ to $98.24 \%$ with an increase in the loading of prepared sample from 0.1 to $1.0 \mathrm{~g} \mathrm{~L}^{-1}$ within 45 min reaction time. Furthermore, based on a great agreement with pseudofirst-order kinetic model, Fig. 6(b) shows the plot of reaction rate constant $\left(K_{\text {app }}\right)$ increases from 0.0082 to $0.0959 \mathrm{~min}^{-1}$ with enhancing catalyst dose in the system. However, with extra $\mathrm{BiOI}_{0.5} \mathrm{Cl}_{0.5}$ dosages of $1.0 \mathrm{~g} \mathrm{~L} \mathrm{~L}^{-1}$, the degradation of BPAF slightly changes comparing to the chemical oxidation process with $0.5 \mathrm{~g} \mathrm{~L}^{-1}$ catalyst dosage addition. The observation can be justified by two convincing reasons. ${ }^{\mathbf{5 0 , 5 1}}$ First of all, the higher of catalyst provides an overly active site of premenstrual syndrome and BPAF adsorption, then the PMS molecule breaks down into more free sulfate radicals. On the other hand, it might be due to the fact that there is a limit to the amount of PMS and the saturated active sites on the catalyst surface are superfluous, which is accordant with the trend of reaction rate constant. In this section, considering the maximum removal of BPAF, the most suitable catalyst dosage is $0.5 \mathrm{~g} \mathrm{~L}^{-1}$ for the further oxidation experiments.

3.3.2 Effect of PMS loading. BPAF removal in PMS/ $\mathrm{BiOI}_{0.5} \mathrm{Cl}_{0.5}$ system was performed with $0.5 \mathrm{~g} \mathrm{~L}^{-1}$ of catalyst and various loadings of PMS during 45 min reaction, the effect of molar of PMS/BPAF on the catalytic degradation efficiency is shown in Fig. 7(a). Increasing molar ratio of PMS/BPAF from 1 to 5 continually enhances the BPAF degradation efficiency. When PMS/BPAF equals 5, BPAF degradation efficiency could reach $96.61 \%$ at $45 \mathrm{~min}$. Nevertheless, with the further increasing molar ratio of PMS/BPAF to 10 or 20, the degradation efficiency is not promoted any more, which can be confirmed by the reaction rate constant dropped from $0.0772 \mathrm{~min}^{-1}$ to $0.0445 \mathrm{~min}^{-1}$ in Fig. 7(b). The reason might own to the invalid PMS scavenging, self-quenching of sulfate and hydroxyl radicals 

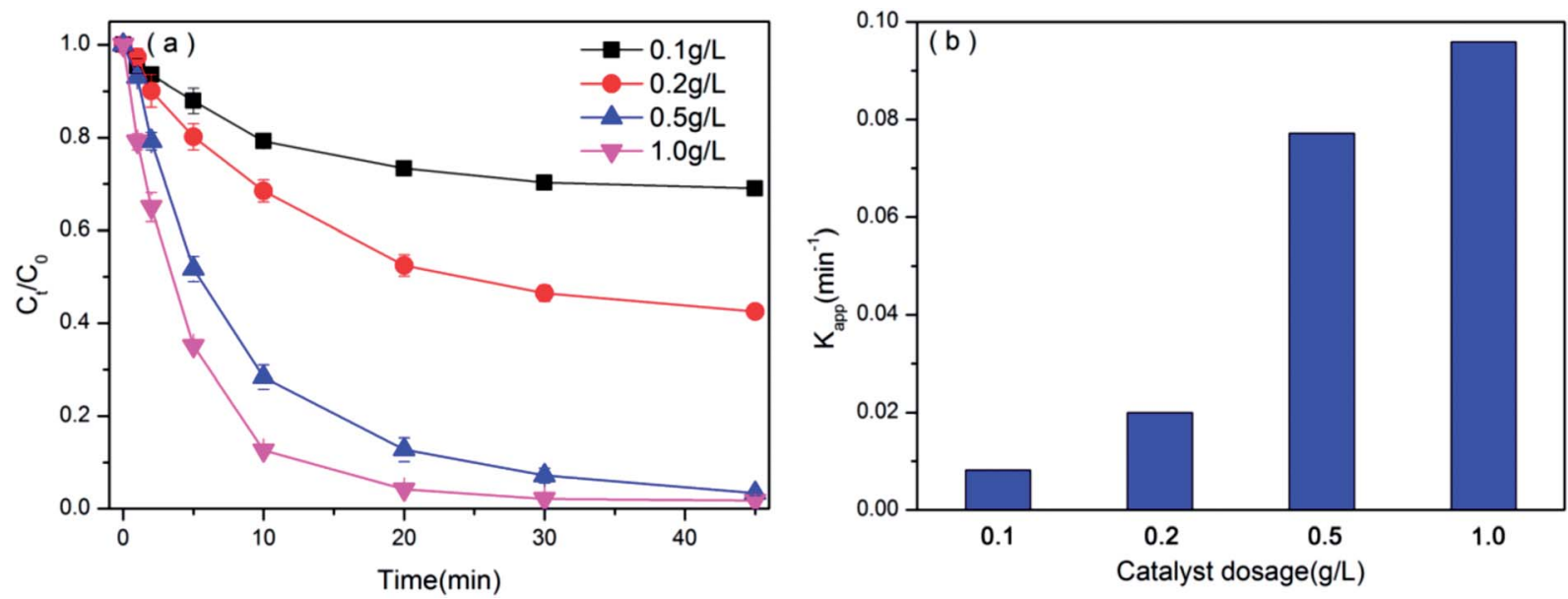

Fig. 6 (a) The degradation efficiencies of BPAF by varying the $\mathrm{BiOl}_{0.5} \mathrm{Cl}_{0.5}$ dosage $\left([\mathrm{BPAF}]=10 \mathrm{mg} \mathrm{L}{ }^{-1}, \mathrm{PMS} / \mathrm{BPAF}=5 / 1, \mathrm{BiOl}{ }_{0.5} \mathrm{Cl} \mathrm{Cl}_{0.5}\right.$ dosage $=$ $0.1-1.0 \mathrm{~g} \mathrm{~L}^{-1}, T=298 \mathrm{~K}$, initial $\mathrm{pH}=7.50$ ) and (b) the degradation rate of pseudo-first-order $K_{\text {app }}$ versus catalyst dosage.

is possible when excessive PMS is added (eqn (2) and (3))..$^{22,53}$ Moreover, the reaction (eqn (4)) and the recombination (eqn (5) and (6)) between both sulfate and hydroxyl radicals also play an important role in decreasing the catalytic performance of process. ${ }^{12,50}$ Hence, the optimal molar ratio of PMS/BPAF is 5.

$$
\begin{gathered}
\mathrm{HSO}_{5}^{-}+\cdot \mathrm{SO}_{4}^{-} \rightarrow \cdot \mathrm{SO}_{5}^{-}+\mathrm{H}^{+} \\
\mathrm{HSO}_{5}^{-}+\cdot \mathrm{OH} \rightarrow \cdot \mathrm{SO}_{5}^{-}+\mathrm{H}_{2} \mathrm{O} \\
\cdot \mathrm{SO}_{4}^{-}+\cdot \mathrm{OH} \rightarrow \mathrm{HSO}_{4}^{-}+1 / 2 \mathrm{O}_{2} \\
\cdot \mathrm{SO}_{4}^{-}+\cdot \mathrm{SO}_{4}^{-} \rightarrow 2 \mathrm{SO}_{4}^{2-} \text { or } \mathrm{S}_{2} \mathrm{O}_{8}^{2-} \\
\cdot \mathrm{OH}+\cdot \mathrm{OH} \rightarrow \mathrm{H}_{2} \mathrm{O}_{2}
\end{gathered}
$$

3.3.3 Effect of solution pH. As BPAF degradation by PMS/ $\mathrm{BiOI}_{0.5} \mathrm{Cl}_{0.5}$ system is an aqueous reaction, and natural wastewater has inconstant $\mathrm{pH}$ values, $\mathrm{pH}$ value is one of the most important influence aspects on chemical reaction rate. Hence, it is necessary to investigate the influence of $\mathrm{pH}$ on the degradation efficiency of BPAF. It must be noted that the addition of acidic PMS into an unbuffered aqueous solution will lead to a significant decrease in the solution $\mathrm{pH}$. As shown in the Fig. 8(a), one of the $\mathrm{pH}$ values of 7.50 was the initial $\mathrm{pH}$ of the solution, the effect of initial solution $\mathrm{pH}$ on BPAF removal was examined in the range of 4.00 to 10.00 . The $k_{1}$ at $\mathrm{pH}_{0}=6.04$ and $\mathrm{pH}_{0}=8.00$ is 0.0662 and $0.0729 \mathrm{~min}^{-1}$, respectively, which is close to the $k_{1}$ at initial pH 7.50 as $0.0772 \mathrm{~min}^{-1}$, suggesting that PMS remained stable under the relatively neutral conditions. However, when the solution became more acidic at $\mathrm{pH}_{0}=4.00$, the degradation extent and kinetics were significantly decreased as $k_{1}$ became $0.0487 \mathrm{~min}^{-1}$, which might be caused by the slower PMS activation at relatively low $\mathrm{pH}$ values. Previous studies have shown that PMS is believed to be more stable under acidic conditions. ${ }^{54}$ With the increase of the solution $\mathrm{pH}$, the dominant PMS species changes from $\mathrm{HSO}_{5}{ }^{-\cdot}$ to $\mathrm{SO}_{5}{ }^{2-\cdot}{ }^{55} \mathrm{In}$ addition, the degradation rate of BPAF increased significantly from $\mathrm{pH} 8.00$ to 9.98, at the alkaline condition, the base activation of PMS could significantly accelerate BPAF degradation
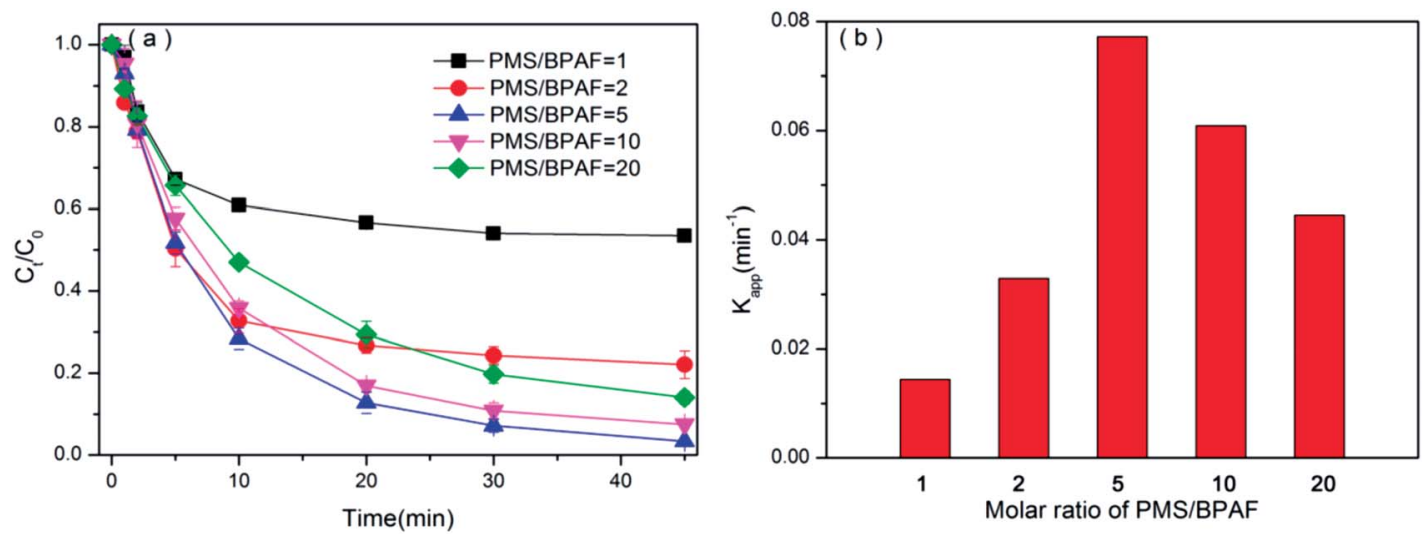

Fig. 7 (a) The degradation efficiencies of BPAF by varying the molar ratio of PMS/BPAF ([BPAF] $=10 \mathrm{mg} \mathrm{L}^{-1}, \mathrm{BiOl}_{0.5} \mathrm{Cl}_{0.5} \mathrm{dosage}=0.5 \mathrm{~g} \mathrm{~L}{ }^{-1}, \mathrm{PMS} /$ $\mathrm{BPAF}=1-20, T=298 \mathrm{~K}$, initial $\mathrm{pH}=7.50$.) and (b) the degradation rate of pseudo-first-order $K_{\text {app }}$ versus the molar ratio of PMS/BPAF. 
( a )

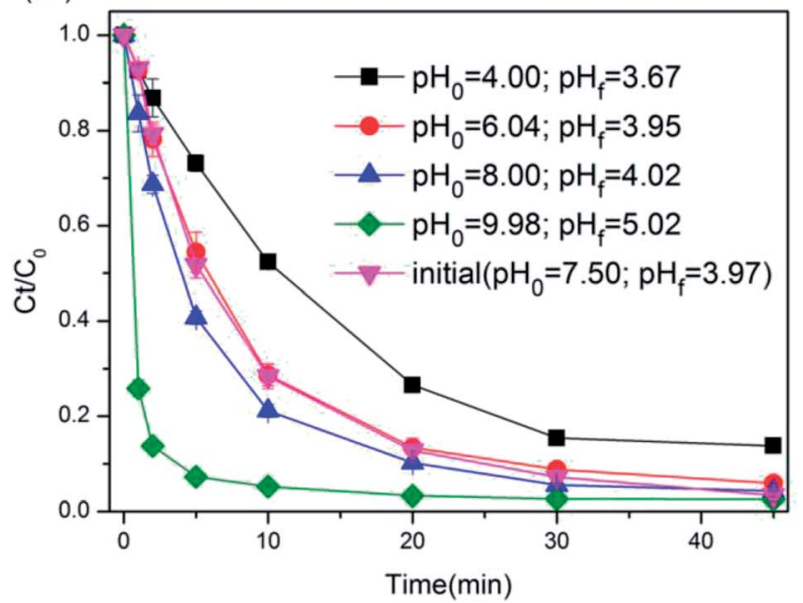

(b)

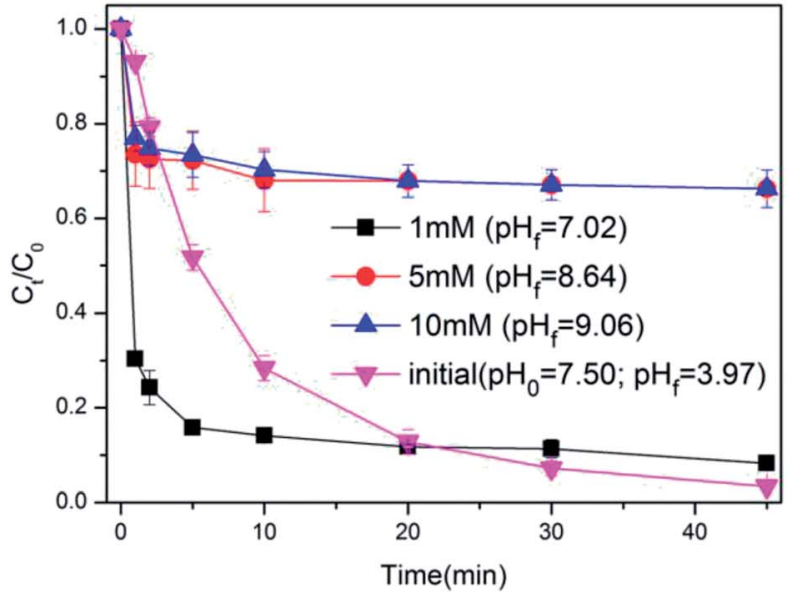

Fig. 8 Effect of initial solution $\mathrm{pH}(\mathrm{a})$ and bicarbonate ion concentration (b) on $\mathrm{BPAF}$ removal efficiency $\left([\mathrm{BPAF}]=10 \mathrm{mg} \mathrm{L}^{-1}, \mathrm{BiOl}_{0.5} \mathrm{Cl}_{0.5}\right.$ dosage $\left.=0.5 \mathrm{~g} \mathrm{~L}^{-1}, \mathrm{PMS} / \mathrm{BPAF}=5,\left[\mathrm{HCO}_{3}^{-}\right]=0-10 \mathrm{mM}, T=298 \mathrm{~K}\right)$.

process, which was similar to the previous study on the degradation of benzoic acid using the UV/PMS process. ${ }^{56}$ In this study, the isoelectric point of $\mathrm{BiOI}_{0.5} \mathrm{Cl}_{0.5}$ was obtained as $5.6 \mathrm{~V}$ (illustrated in Fig. S5 $\dagger$ through zeta potential detection), above which the surface charge was negative and below which the catalyst surface was positive. On the other hand, the $\mathrm{p} K_{\mathrm{a}}$ of BPAF values of 9.13 and $9.74 .{ }^{57}$ Therefore, the excellent performance of alkaline $\mathrm{pH}$ can be attributed to several factors. Firstly, it was easier to activate a larger fraction of $\mathrm{SO}_{5}{ }^{2-\cdot}$ ions compared to $\mathrm{HSO}_{5}{ }^{-\cdot}$ with the base activation of PMS. Secondly, the electrostatic repulsion existed between the catalyst surface and BPAF when $\mathrm{pH}$ greater than 9.74, thus the suppression effect of increasing BPAF removal was very weak at the alkaline condition from $\mathrm{pH} 8.00$ to 9.98. Finally, the strong hydroxyl radical at basic pH from sulfate (eqn (7)) also accelerated BPAF degradation efficiency. ${ }^{58}$

$$
\mathrm{OH}^{-}+\cdot \mathrm{SO}_{4}^{-} \rightarrow \cdot \mathrm{OH}+\mathrm{SO}_{4}^{2-}
$$

3.3.4 Effect of the various anions. To investigate the effect of the various anions in the degradation of BPAF in PMS/ BiOI ${ }_{0.5} \mathrm{Cl}_{0.5}$ system, 0-10 $\mathrm{mM} \mathrm{Cl}{ }^{-}, \mathrm{NO}_{3}{ }^{-}, \mathrm{SO}_{4}{ }^{2-}$ and $\mathrm{HCO}_{3}{ }^{-}$ were selected. Compared with $\mathrm{Cl}^{-}, \mathrm{NO}_{3}{ }^{-\cdot}$ and $\mathrm{SO}_{4}{ }^{2-}$ as shown in Fig. S6, $\uparrow$ a significantly inhibition effect of BPAF degradation was observed when dosing $\mathrm{HCO}_{3}{ }^{-\cdot}$ shown in Fig. 8(b), and the inhibition was enhanced with increasing $\mathrm{HCO}_{3}{ }^{-\cdot}$ concentration. It is well known that bicarbonate strongly influence solution $\mathrm{pH}$. Of note, once $\mathrm{HCO}_{3}{ }^{-\cdot}$ ions were added to the solution, carbonate would be formed and the solution eventually reached the highly $\mathrm{pH}$ remained at 7.0-9.0 because of dynamic equilibrium. According to previous studies, $\mathrm{HCO}_{3}{ }^{-\cdot}$ is an effective scavenger for sulfate radicals $\left(\cdot \mathrm{SO}_{4}{ }^{-}\right)$and hydroxyl radicals $(\cdot \mathrm{OH})$ (eqn. (8)-(11)), which can lead to an inhibitory effect on contaminant degradation. ${ }^{59}$ When added $1 \mathrm{mM} \mathrm{HCO}_{3}{ }^{-\cdot}$ to the solution, the reaction system was changed to alkaline circumstance, which created excellent reaction condition for the activation of PMS, resulting in the significant increase of the reaction rate, ${ }^{60}$ and the result was similar to the image of $\mathrm{pH}=9$ in Fig. 8(a). While with the introduction of high dosage of $\mathrm{HCO}_{3}{ }^{-\cdot}(5 \mathrm{mM}$ and $10 \mathrm{mM})$, the BPAF removal was inhibited distinctly, because the $\mathrm{HCO}_{3}{ }^{-\cdot}$ would act as a scavenger for a large proportion of sulfate radicals $\left(\cdot \mathrm{SO}_{4}{ }^{-}\right)$and hydroxyl radicals $(\cdot \mathrm{OH})$.

$$
\begin{gathered}
\mathrm{HCO}_{3}^{-}+\cdot \mathrm{SO}_{4}^{-} \rightarrow \cdot \mathrm{HCO}_{3}+\mathrm{SO}_{4}^{2-} \\
\mathrm{CO}_{3}^{2-}+\cdot \mathrm{SO}_{4}^{-} \rightarrow \cdot \mathrm{CO}_{3}^{-}+\mathrm{SO}_{4}^{2-} \\
\mathrm{HCO}_{3}^{-}+\cdot \mathrm{OH} \rightarrow \cdot \mathrm{CO}_{3}^{-}+\mathrm{H}_{2} \mathrm{O} \\
\mathrm{CO}_{3}^{2-}+\cdot \mathrm{OH} \rightarrow \cdot \mathrm{CO}_{3}^{-}+\mathrm{OH}^{-}
\end{gathered}
$$

3.3.5 Effect of water matrices. To investigate the realistic conditions, the effect of various water matrices including tap water and surface water (from the Minyuan Lake in Sichuan University) on the removal of BPAF was studied using the PMS/ $\mathrm{BiOI}_{0.5} \mathrm{Cl}_{0.5}$ system, as shown in Fig. $\mathrm{S} 7, \dagger$ the $\mathrm{pH}$ of tap water and surface water is 8.05 and 8.83 , respectively. The degradation rate of $\mathrm{BPAF}$ was very fast in the first $5 \mathrm{~min}$. However, the removal of $\mathrm{BPAF}$ in the $\mathrm{PMS} / \mathrm{BiOI}_{0.5} \mathrm{Cl}_{0.5}$ system was restrained about $10 \%$ in tap water and surface water, which was presumably related to the high TOC levels of tap water $\left(5.57 \mathrm{mg} \mathrm{L}^{-1}\right)$ and surface water $\left(6.87 \mathrm{mg} \mathrm{L}^{-1}\right)$. The main constituents of TOC were involved in hydrophobic, transphilic and hydrophilic DOCs, ${ }^{61}$ where they can compete with BPAF for $\cdot \mathrm{OH}$ and $\cdot \mathrm{SO}_{4}{ }^{-} \cdot$ radicals. Moreover, it is notable that in spite of the higher TOC levels in the two water samples, the $\mathrm{PMS} / \mathrm{BiOI}_{0.5} \mathrm{Cl}_{0.5}$ system showed high catalytic performance on BPAF removal, indicating that the present reaction system shows the great potential of cleaning BPAF wastewater on the basis of advanced oxidation process. 


\subsection{Recyclability of catalyst to degrade the BPAF}

In order to evaluate the reusability of $\mathrm{BiOI}_{0.5} \mathrm{Cl}_{0.5}$ sample, the catalyst was collected by filtration from aqueous solution, washed by ethanol and ultrapure water, then reused for degradation tests. Fig. S8† shows four recycling runs of the BPAF degradation, it was noticeable that the regeneration efficiency (defined as $\left(1-C_{t} / C_{0}\right) \%$ ) remained about $47.5 \%$ after 4 cycles. The removal of BPAF were decreased $14.53 \%, 42.05 \%$ and $49.10 \%$ after each recycling, respectively. This activity decrease in the regeneration efficiency is possible due to the remarkable amounts of both BPAF molecules and by-products are adsorbed on the surface of catalyst, then the catalytic surface activity and the rate of mineralization are limited. Furthermore, some pores on the catalyst surface were blocked, due to the adsorption of BPAF and intermediates from degradation. ${ }^{62}$

\subsection{The mechanism of $\mathrm{BiOI}_{0.5} \mathrm{Cl}_{0.5}$ to active PMS for degradation of BPAF}

3.5.1 Identification of the reactive species. For the PMS/ $\mathrm{BiOI}_{0.5} \mathrm{Cl}_{0.5}$ system, it was expected that hydroxyl and/or sulfate radicals can be produced and then react with BPAF molecules. To identify the oxidation of the reaction system, ESR experiment using 5,5-dimethy-1-pyrroline (DMPO) as a radical spin trapping agent were performed. As shown in Fig. 9, the characteristic signals of 5,5-dimethy-2-pyrroline- $N$-oxyl (DMPOX) with heptet were detected at $3 \mathrm{~min}$, which were formed by the oxidation of DMPO, ${ }^{63}$ indicating that some strong ROS were produced in the reaction system. Previous studies had proposed transformation pathway of DMPO to DMPOX. ${ }^{64,65}$ The fact that we did not yet detect $\cdot \mathrm{OH} / \cdot \mathrm{SO}_{4}{ }^{-\cdot}$ radicals via the ESR test, which did not mean that they were absent. In addition, the signals of DMPOX with heptet were more obvious after adding $\mathrm{NaF}$, which proved that the surface radicals played an important role in the process of degradation of BPAF.

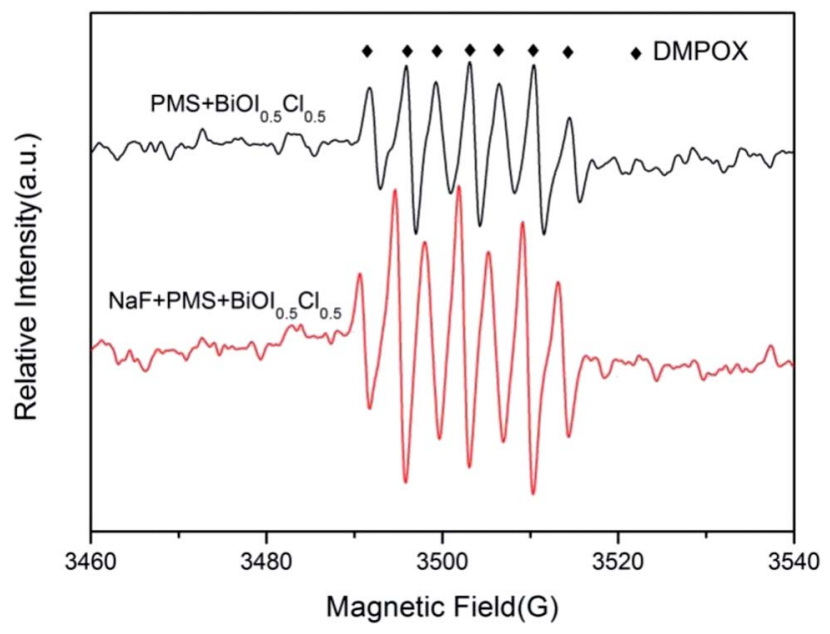

Fig. 9 ESR spectra of $\mathrm{BiOl}_{0.5} \mathrm{Cl}_{0.5} / \mathrm{PMS}$ and $\mathrm{BiOl}_{0.5} \mathrm{Cl}_{0.5} / \mathrm{PMS} / \mathrm{NaF}$ system $\left(\mathrm{BiOl}_{0.5} \mathrm{Cl}_{0.5}\right.$ dosage $=0.5 \mathrm{~g} \mathrm{~L}^{-1}, \mathrm{PMS}=0.3 \mathrm{mM},[\mathrm{NaF}]=$ $0.03 \mathrm{~mol} \mathrm{~L}^{-1}, T=298 \mathrm{~K}$ ).
To distinguish contribution of hydroxyl and/or sulfate radicals to BPAF degradation, the radical intermediates were probed via radical quenching tests: excess tert-butyl alcohol (TBA) and methanol (MA) were added into the reaction solution as radical scavengers. MA, a kind of alcohol containing an $\alpha$-hydrogen, can react with $\cdot \mathrm{SO}_{4}{ }^{-\cdot}$ and $\cdot \mathrm{OH}$ at significant rates $\left(k \cdot \mathrm{SO}_{4}{ }^{-} / \mathrm{MA}=\right.$ $\left.1.6-7.7 \times 10^{7} \mathrm{M}^{-1} \mathrm{~s}^{-1}, k \cdot \mathrm{OH} / \mathrm{MA}=1.2-2.8 \times 10^{9} \mathrm{M}^{-1} \mathrm{~s}^{-1}\right)$ while TBA is an specific scavenger for $\cdot \mathrm{OH}\left(k \cdot \mathrm{OH} / \mathrm{TBA}=3.8-7.6 \times 10^{8}\right.$ $\left.\mathrm{M}^{-1} \mathrm{~s}^{-1}\right){ }^{66}$ Fig. 10(a) showed that the inhibiting effects of BPAF degradation were not obvious when MA or TBA was added into the $\mathrm{BiOI}_{0.5} \mathrm{Cl}_{0.5} / \mathrm{PMS}$ suspensions. $14.57 \%$ and $9.21 \%$ of the BPAF degradation were inhibited by MA and TBA, respectively. The reason may be that hydrophilic MA and TBA are superior to competing for free radicals in the liquid phase rather than for large reaction with active radicals on the surface of the catalyst. However, from the inner figure of Fig. 10(a), $k_{1}$ value decreased from 0.0772 to $0.435 \mathrm{~min}^{-1}$, revealing that the PMS activation was inhibited by TBA and $\cdot \mathrm{OH}$ may be involved in BPAF degradation. What's more, in the presence of methanol, $k_{1}$ value decreased to $0.0359 \mathrm{~min}^{-1}$. Therefore, the above results suggest that the methanol adequately suppressed PMS activation and the sulfate and hydroxyl radicals had significant effect on the degradation of BPAF, the primary active species was surface bound $\cdot \mathrm{OH} / \cdot \mathrm{SO}_{4}{ }^{-}$in the catalytic oxidation process. Furthermore, the degradation of the PMS in $\mathrm{BiOI}_{0.5} \mathrm{Cl}_{0.5} / \mathrm{PMS}$ and $\mathrm{BiOI}_{0.5} \mathrm{Cl}_{0.5} / \mathrm{PMS} / \mathrm{BPAF}$ system was detected. As shown in the Fig. $S 9, \dagger$ the degradation rate of PMS increased $18.31 \%$ after adding BPAF, indicating that the PMS was involved in the reaction.

\subsubsection{The mechanism discussion}

To further analyze the role of surface bound $\cdot \mathrm{OH} / \cdot \mathrm{SO}_{4}{ }^{-}$. generated by the surface of the synthesized $\mathrm{BiOI}_{0.5} \mathrm{Cl}_{0.5}$, different concentrations of $\mathrm{NaF}$ were added to the solution. Previous researches had shown that $\mathrm{F}^{-}$in the solution could desorb $\cdot \mathrm{OH}$ bound on catalyst by forming strong fluorideexchange. ${ }^{67,68}$ As expected in Fig. 10(b) and S9(a), $\uparrow$ the addition of $\mathrm{F}^{-}$improved the BPAF degradation and with the more NaF dosage, the more obvious of the PMS degradation effect, the degradation rate of PMS increased $18.20 \%$ compared with $\mathrm{BiOI}_{0.5} \mathrm{Cl}_{0.5} / \mathrm{PMS} / \mathrm{BPAF}$ system. While there was no obvious promotion in degradation of PMS when adding MA or TBA (shown in Fig. S9(b) $\dagger$ ). It should be pointed out that, after $\mathrm{F}^{-}$ surface modification, the reduce of surface free radicals might promote the production of radicals in bulk. The results indicated PMS mainly bonded with the active sites of the $\mathrm{BiOI}_{0.5} \mathrm{Cl}_{0.5}$ catalyst to generate the surface radicals, which were important rather than the radicals in bulk for BPAF degradation.

Thus, a possible catalysis mechanism of PMS activation by $\mathrm{BiOI}_{0.5} \mathrm{Cl}_{0.5}$ for BPAF degradation are proposed. Because PMS is an acidic oxidant with standard reduction potentials for the aqueous half-reactions, which was mainly in the form of $\mathrm{HSO}_{5}{ }^{-}$ and $\mathrm{SO}_{5}{ }^{2-}$ ions in the solution (eqn (12) and (13)). $\mathrm{HSO}_{5}{ }^{-}$and $\mathrm{SO}_{5}{ }^{2-}$ were adsorbed on the surface of the $\mathrm{BiOI}_{0.5} \mathrm{Cl}_{0.5}$ due to the electrostatic attraction, which were easily activated by $\mathrm{Bi}^{3+} / \mathrm{Bi}^{5+}$ couples to generate $\cdot \mathrm{SO}_{4}{ }^{-}$and $\cdot \mathrm{SO}_{5}{ }^{-}$(eqn. (14)-(16)). Under 

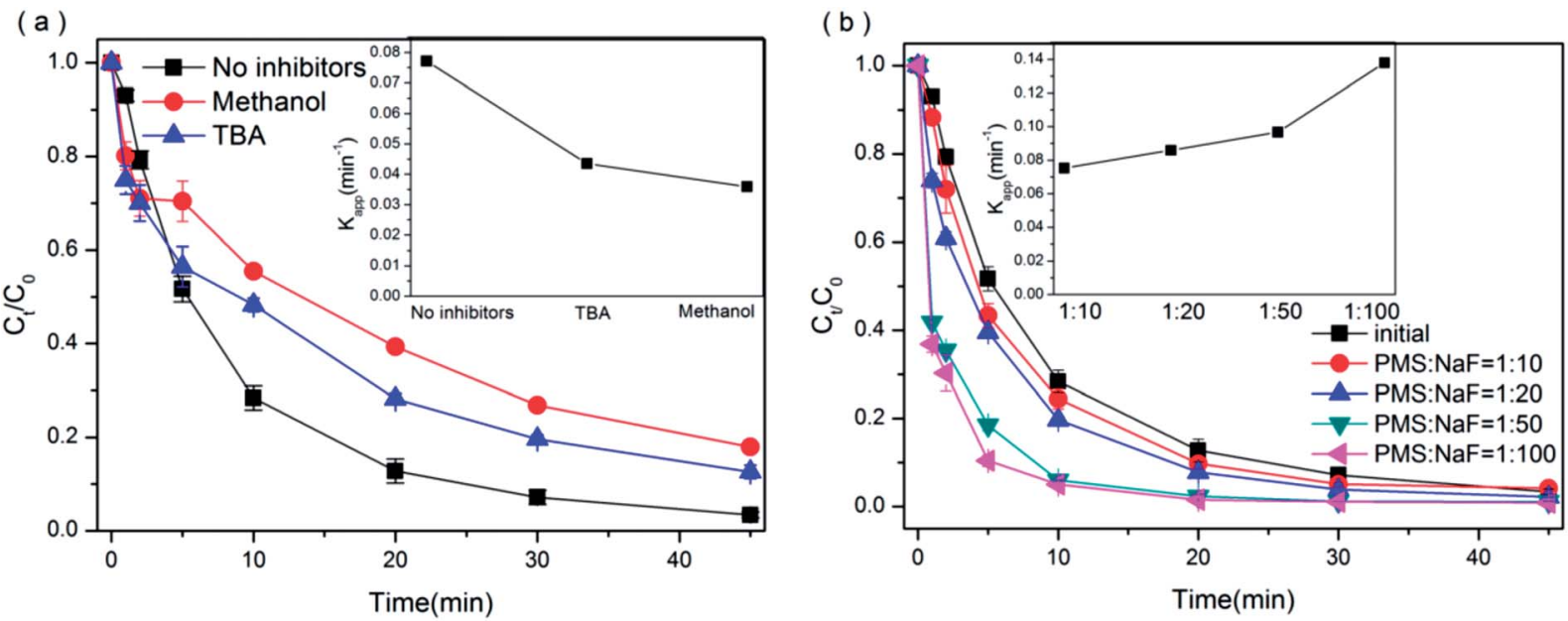

Fig. 10 (a) BPAF degradation in the presence of methanol and TBA as a radical scavenger and (b) in $\mathrm{NaF} / \mathrm{PMS} / \mathrm{BiOl}_{0.5} \mathrm{Cl} 0.5 \mathrm{system}$. ([BPAF] $=$ $10 \mathrm{mg} \mathrm{L}^{-1}, \mathrm{BiOl}_{0.5} \mathrm{Cl}_{0.5}$ dosage $=0.5 \mathrm{~g} \mathrm{~L}^{-1}, \mathrm{PMS} / \mathrm{BPAF}=5$, [methanol] $\left.=[\mathrm{TBA}]=0.075 \mathrm{~mol} \mathrm{~L}-1,[\mathrm{NaF}]=0-0.015 \mathrm{~mol} \mathrm{~L}-1, T=298 \mathrm{~K}\right)$.

strong alkaline conditions, $\cdot \mathrm{OH}$ turns out to be the major radical, as shown in eqn (17). In addition, the formation of $\cdot \mathrm{OH}$, which also can be attributed to reaction between $\cdot \mathrm{SO}_{4}{ }^{-}$and water (eqn (18)). ${ }^{69,70}$ Finally, $\cdot \mathrm{OH}$ and $\cdot \mathrm{SO}_{4}{ }^{-}$on surface of the catalyst attacked adsorbed BPAF organic compounds and triggered a series of further degradations. Based on the above results, a feasible mechanism for the degradation of BPAF concerning the interaction between $\mathrm{BiOI}_{0.5} \mathrm{Cl}_{0.5}$ and $\mathrm{PMS}$ is proposed in Fig. 11.

$$
\begin{gathered}
\mathrm{HSO}_{5}^{-}+\mathrm{H}^{+}+2 \mathrm{e}^{-} \rightarrow \mathrm{SO}_{4}^{2-}+\mathrm{H}_{2} \mathrm{O} \\
\mathrm{SO}_{5}^{2-}+\mathrm{H}_{2} \mathrm{O}+2 \mathrm{e}^{-} \rightarrow \mathrm{SO}_{4}^{2-}+\mathrm{OH}^{-} \\
\equiv \mathrm{Bi}^{3+}+2 \mathrm{HSO}_{5}^{-} \rightarrow 2 \cdot \mathrm{SO}_{4}^{-}+\equiv \mathrm{Bi}^{5+}+2 \mathrm{OH}^{-} \\
\equiv \mathrm{Bi}^{5+}+2 \mathrm{HSO}_{5}^{-} \rightarrow 2 \cdot \mathrm{SO}_{5}^{-}+\equiv \mathrm{Bi}^{3+}+2 \mathrm{H}^{+} \\
2 \cdot \mathrm{SO}_{5}^{-} \rightarrow 2 \cdot \mathrm{SO}_{4}^{-}+\mathrm{O}_{2} \\
\cdot \mathrm{SO}_{4}^{-}+\mathrm{OH}^{-} \rightarrow \mathrm{SO}_{4}^{2-}+\cdot \mathrm{OH}
\end{gathered}
$$

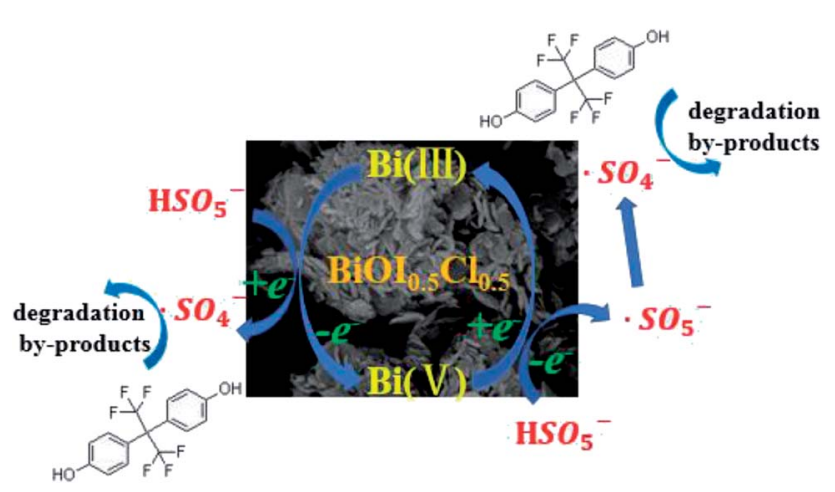

Fig. 11 Proposed mechanism of BPAF degradation in the $\mathrm{BiOl}_{0.5} \mathrm{Cl}_{0.5} /$ PMS process.

$$
\begin{gathered}
\cdot \mathrm{SO}_{4}^{-}+\mathrm{H}_{2} \mathrm{O} \rightarrow \mathrm{SO}_{4}^{2-}+\mathrm{H}^{+}+\cdot \mathrm{OH} \\
\mathrm{BPAF}+\cdot \mathrm{SO}_{4}^{-} / \cdot \mathrm{OH} \rightarrow \text { degraded products }
\end{gathered}
$$

\section{Conclusion}

The obtained results showed that the synthesized catalyst had a good catalytic performance in the activation of PMS to degrade BPAF. Under optimum experimental conditions, the removal efficiencies of BPAF, TOC were found to be 99.1 and $43.9 \%$, respectively. This degradation activity could be enhanced by increasing catalyst dose and initial solution $\mathrm{pH}$. Bicarbonate ions adversely affected the degradation rate of BPAF, while chloride, nitrate and sulfate ions did not represent any effect on the removal of BPAF. In the tap water and surface water, the present reaction system still showed the great potential of cleaning BPAF wastewater. Radical scavengers' experiments verified the dominant active species generated in the $\mathrm{BiOI}_{0.5^{-}}$ $\mathrm{Cl}_{0.5} / \mathrm{PMS}$ system were surface-bound $\cdot \mathrm{SO}_{4}{ }^{-\cdot}$ and $\cdot \mathrm{OH}$ radicals, thus a possible degradation mechanism of BPAF was proposed. In conclusion, the study provides an option and would be a promising effective technology for BPAF removal.

\section{Conflicts of interest}

There are no conflicts of interest to declare.

\section{Acknowledgements}

This work was financially supported by the National Natural Science Foundation of China (No. 51508354) and the Science and Technology Projects of Chengdu (No. 2015-HM01-00536$\mathrm{SF}$ ). The authors are thankful to all the anonymous reviewers for their insightful comments and suggestions. 


\section{References}

1 J. R. Rochester, Bisphenol A and human health: a review of the literature, Reprod. Toxicol., 2013, 42, 132-155.

2 J. R. Rochester and A. L. Bolden, Bisphenol S and F: A Systematic Review and Comparison of the Hormonal Activity of Bisphenol A Substitutes, Environ. Health Perspect., 2015, 123(7), 643-650.

3 E. M. Rodriguez, G. Fernandez, N. Klamerth, M. I. Maldonado, P. M. Alvarez and S. Malato, Efficiency of different solar advanced oxidation processes on the oxidation of bisphenol A in water, Appl. Catal., B, 2010, 95(3-4), 228-237.

4 C. Y. Wang, H. Zhang, F. Li and L. Y. Zhu, Degradation and Mineralization of Bisphenol A by Mesoporous $\mathrm{Bi}_{2} \mathrm{WO}_{6}$ under Simulated Solar Light Irradiation, Environ. Sci. Technol., 2010, 44(17), 6843-6848.

5 J. Michalowicz, Bisphenol A - sources, toxicity and biotransformation, Environ. Toxicol. Pharmacol., 2014, 37(2), 738-758.

6 J. R. Kim, S. G. Huling and E. Kan, Effects of temperature on adsorption and oxidative degradation of bisphenol $\mathrm{A}$ in an acid-treated iron-amended granular activated carbon, Chem. Eng. J., 2015, 262, 1260-1267.

7 C. Huang, P. Xu, G. M. Zeng, D. L. Huang, C. Lai, M. Cheng, et al., The rapid degradation of bisphenol A induced by the response of indigenous bacterial communities in sediment, Appl. Microbiol. Biotechnol., 2017, 101(9), 39193928.

8 C. Y. Wang, L. Y. Zhu, C. Song, G. Q. Shan and P. Chen, Characterization of photocatalyst $\mathrm{Bi}_{3.84} \mathrm{~W}_{0.16} \mathrm{O}_{6.24}$ and its photodegradation on bisphenol A under simulated solar light irradiation, Appl. Catal., B, 2011, 105(1-2), 229-236.

9 C. Y. Wang, X. Zhang, H. B. Qiu, W. K. Wang, G. X. Huang, J. Jiang, et al., Photocatalytic degradation of bisphenol A by oxygen-rich and highly visible-light responsive $\mathrm{Si}_{12} \mathrm{O}_{17} \mathrm{C}_{12}$ nanobelts, Appl. Catal., B, 2017, 200, 659-665.

10 E. B. Simsek, Solvothermal synthesized boron doped $\mathrm{TiO}_{2}$ catalysts: photocatalytic degradation of endocrine disrupting compounds and pharmaceuticals under visible light irradiation, Appl. Catal., B, 2017, 200, 309-322.

11 S. Akbari, F. Ghanbari and M. Moradi, Bisphenol A degradation in aqueous solutions by electrogenerated ferrous ion activated ozone, hydrogen peroxide and persulfate: applying low current density for oxidation mechanism, Chem. Eng. J., 2016, 294, 298-307.

12 J. Sharma, I. M. Mishra, D. D. Dionysiou and V. Kumar, Oxidative removal of Bisphenol A by UV-C/ peroxymonosulfate (PMS): kinetics, influence of co-existing chemicals and degradation pathway, Chem. Eng. J., 2015, 276, 193-204.

13 Y. X. Feng, J. Yin, Z. H. Jiao, J. C. Shi, M. Li and B. Shao, Bisphenol AF may cause testosterone reduction by directly affecting testis function in adult male rats, Toxicol. Lett., 2012, 211(2), 201-209.
14 T. Ruan, D. Liang, S. J. Song, M. Y. Song, H. L. Wang and G. B. Jiang, Evaluation of the in vitro estrogenicity of emerging bisphenol analogs and their respective estrogenic contributions in municipal sewage sludge in China, Chemosphere, 2015, 124, 150-155.

15 C. Y. Liao and K. Kannan, Concentrations and Profiles of Bisphenol A and Other Bisphenol Analogues in Foodstuffs from the United States and Their Implications for Human Exposure, J. Agric. Food Chem., 2013, 61(19), 4655-4662.

16 S. K. Khetan and T. J. Collins, Human pharmaceuticals in the aquatic environment: a challenge to green chemistry, Chem. Rev., 2007, 107(6), 2319-2364.

17 Z. M. Ding, X. F. Jiao, D. Wu, J. Y. Zhang, F. Chen, Y. S. Wang, et al., Bisphenol AF negatively affects oocyte maturation of mouse in vitro through increasing oxidative stress and DNA damage, Chem.-Biol. Interact., 2017, 278, 222-229.

18 M. Ahmad, A. L. Teel and R. J. Watts, Mechanism of Persulfate Activation by Phenols, Environ. Sci. Technol., 2013, 47(11), 5864-5871.

19 H. Zhong, M. L. Brusseau, Y. K. Wang, N. Yan, L. Quig and G. R. Johnson, In situ activation of persulfate by iron filings and degradation of 1,4-dioxane, Water Res., 2015, 83, 104-111.

20 J. Liu, J. H. Zhou, Z. X. Ding, Z. W. Zhao, X. Xu and Z. D. Fang, Ultrasound irritation enhanced heterogeneous activation of peroxymonosulfate with $\mathrm{Fe}_{3} \mathrm{O}_{4}$ for degradation of azo dye, Ultrason. Sonochem., 2017, 34, 953959.

21 A. J. Jafari, B. Kakavandi, N. Jaafarzadeh, R. R. Kalantary, M. Ahmadi and A. A. Babaei, Fenton-like catalytic oxidation of tetracycline by $\mathrm{AC} @ \mathrm{Fe}_{3} \mathrm{O}_{4}$ as a heterogeneous persulfate activator: adsorption and degradation studies, $J$. Ind. Eng. Chem., 2017, 45, 323-333.

22 Y. B. Wang, X. Zhao, D. Cao, Y. Wang and Y. F. Zhu, Peroxymonosulfate enhanced visible light photocatalytic degradation bisphenol A by single-atom dispersed $\mathrm{Ag}$ mesoporous g- $\mathrm{C}_{3} \mathrm{~N}_{4}$ hybrid, Appl. Catal., B, 2017, 211, 79-88.

23 P. D. Hu and M. C. Long, Cobalt-catalyzed sulfate radicalbased advanced oxidation: a review on heterogeneous catalysts and applications, Appl. Catal., B, 2016, 181, 103117.

24 P. H. Shao, J. Y. Tian, X. G. Duan, Y. Yang, W. X. Shi, X. B. Luo, et al., Cobalt silicate hydroxide nanosheets in hierarchical hollow architecture with maximized cobalt active site for catalytic oxidation, Chem. Eng. J., 2019, 359, 79-87.

25 J. Kang, H. Y. Zhang, X. G. Duan, H. Q. Sun, X. Y. Tan, S. M. Liu, et al., Magnetic Ni-Co alloy encapsulated Ndoped carbon nanotubes for catalytic membrane degradation of emerging contaminants, Chem. Eng. J., 2019, 362, 251-261.

26 J. Wang, X. G. Duan, Q. Dong, F. P. Meng, X. Y. Tan, S. M. Liu, et al., Facile synthesis of N-doped 3D graphene aerogel and its excellent performance in catalytic degradation of antibiotic contaminants in water, Carbon, 2019, 144, 781-790. 
27 S. S. Zhu, X. C. Huang, F. Ma, L. Wang, X. G. Duan and S. B. Wang, Catalytic Removal of Aqueous Contaminants on N-Doped Graphitic Biochars: Inherent Roles of Adsorption and Nonradical Mechanisms, Environ. Sci. Technol., 2018, 52(15), 8649-8658.

28 L. Q. Ye, Y. R. Su, X. L. Jin, H. Q. Xie and C. Zhang, Recent advances in $\mathrm{BiOX}(\mathrm{X}=\mathrm{Cl}, \mathrm{Br}$ and $\mathrm{I})$ photocatalysts: synthesis, modification, facet effects and mechanisms, Environ. Sci.: Nano, 2014, 1(2), 90-112.

29 W. J. Kim, D. Pradhan, B. K. Min and Y. Sohn, Adsorption/ photocatalytic activity and fundamental natures of $\mathrm{BiOCl}$ and BiOCl$_{x} \mathrm{I}_{1-\mathrm{x}}$ prepared in water and ethylene glycol environments, and $\mathrm{Ag}$ and Au-doping effects, Appl. Catal., B, 2014, 147, 711-725.

30 H. J. Zhang, Y. X. Yang, Z. Zhou, Y. P. Zhao and L. Liu, Enhanced Photocatalytic Properties in BiOBr Nanosheets with Dominantly Exposed (102) Facets, J. Phys. Chem. C, 2014, 118(26), 14662-14669.

31 L. M. Sun, L. Xiang, X. Zhao, C. J. Jia, J. Yang, Z. Jin, et al., Enhanced Visible-Light Photocatalytic Activity of BiOI/ BiOCl Heterojunctions: Key Role of Crystal Facet Combination, ACS Catal., 2015, 5(6), 3540-3551.

32 X. F. Chang, M. A. Gondal, A. A. Al-Saadi, M. A. Ali, H. F. Shen, Q. Zhou, et al., Photodegradation of rhodamine B over unexcited semiconductor compounds of BiOCl and BiOBr, J. Colloid Interface Sci., 2012, 377, 291-298.

$33 \mathrm{H}$. Li and L. Zhang, Photocatalytic performance of different exposed crystal facets of BiOCl, Curr. Opin. Green Sustain. Chem., 2017, 6, 48-56.

34 T. Zhang, S. Chu, J. Li, L. Wang, R. Chen, Y. Shao, et al., Efficient Degradation of Aqueous Carbamazepine by Bismuth Oxybromide-Activated Peroxide Oxidation, Catalysts, 2017, 7(11), 315.

35 X. N. Wang, W. L. Bi, P. P. Zhai, X. B. Wang, H. J. Li, G. Mailhot, et al., Adsorption and photocatalytic degradation of pharmaceuticals by $\operatorname{BiOCl}_{\mathrm{x}} \mathrm{I}_{\mathrm{y}}$ nanospheres in aqueous solution, Appl. Surf. Sci., 2016, 360, 240-251.

36 Y. Y. Zhang, X. G. Sun, G. Z. Yang, Y. H. Zhu, H. Y. Si, J. M. Zhang, et al., Preparation and characterization of bifunctional $\operatorname{BiOCl}_{\mathrm{x}} \mathrm{I}_{\mathrm{y}}$ solid solutions with excellent adsorption and photocatalytic abilities for removal of organic dyes, Mater. Sci. Semicond. Process., 2016, 41, 193199.

37 K. Natarajan, H. C. Bajaj and R. J. Tayade, Photocatalytic efficiency of bismuth oxyhalide ( $\mathrm{Br}, \mathrm{Cl}$ and $\mathrm{I})$ nanoplates for RhB dye degradation under LED irradiation, J. Ind. Eng. Chem., 2016, 34, 146-156.

38 J. Cao, B. Y. Xu, B. D. Luo, H. L. Lin and S. F. Chen, Novel $\mathrm{BiOI} / \mathrm{BiOBr}$ heterojunction photocatalysts with enhanced visible light photocatalytic properties, Catal. Commun., 2011, 13(1), 63-68.

39 J. X. Xia, J. Di, H. T. Li, H. Xu, H. M. Li and S. J. Guo, Ionic liquid-induced strategy for carbon quantum dots/BiOX ( $\mathrm{X}=\mathrm{Br}, \mathrm{Cl}$ ) hybrid nanosheets with superior visible lightdriven photocatalysis, Appl. Catal., B, 2016, 181, 260-269.

40 J. Xie, Y. L. Cao, D. Z. Jia, H. Y. Qin and Z. T. Liang, Roomtemperature solid-state synthesis of BiOCl hierarchical microspheres with nanoplates, Catal. Commun., 2015, 69, 34-38.

41 B. Priya, P. Raizada, N. Singh, P. Thakur and P. Singh, Adsorptional photocatalytic mineralization of oxytetracycline and ampicillin antibiotics using Bi2O3/ BiOCl supported on graphene sand composite and chitosan, J. Colloid Interface Sci., 2016, 479, 271-283.

42 L. Lu, M. Y. Zhou, L. Yin, G. W. Zhou, T. Jiang, X. K. Wan, et al., Tuning the physicochemical property of BiOBr via $\mathrm{pH}$ adjustment: towards an efficient photocatalyst for degradation of bisphenol A, J. Mol. Catal. A: Chem., 2016, 423, 379-385.

43 M. Cui, J. X. Yu, H. J. Lin, Y. Wu, L. H. Zhao and Y. He, In situ preparation of $\mathrm{Z}$-scheme $\mathrm{AgI} / \mathrm{Bi}_{5} \mathrm{O}_{7} \mathrm{I}$ hybrid and its excellent photocatalytic activity, Appl. Surf. Sci., 2016, 387, 912-920.

44 G. C. Chen, M. M. Zhu and X. W. Wei, Photocatalytic properties of attached BiOCl-(001) nanosheets onto $\mathrm{AgBr}$ colloidal spheres toward MO and RhB degradation under an LED irradiation, Mater. Lett., 2018, 212, 182-185.

45 X. Zhang, L. Z. Zhang, T. F. Xie and D. J. Wang, LowTemperature Synthesis and High Visible-Light-Induced Photocatalytic Activity of $\mathrm{BiOI} / \mathrm{TiO}_{2}$ Heterostructures, $J$. Phys. Chem. C, 2009, 113(17), 7371-7378.

46 H. L. Lin, H. F. Ye, X. Li, J. Cao and S. F. Chen, Facile anionexchange synthesis of $\mathrm{BiOI} / \mathrm{BiOBr}$ composite with enhanced photoelectrochemical and photocatalytic properties, Ceram. Int., 2014, 40(7), 9743-9750.

47 Y. Xu, J. Ai and H. Zhang, The mechanism of degradation of bisphenol A using the magnetically separable $\mathrm{CuFe}_{2} \mathrm{O}_{4} /$ peroxymonosulfate heterogeneous oxidation process, $J$. Hazard. Mater., 2016, 309, 87-96.

48 X. Cheng, H. G. Guo, Y. L. Zhang, X. Wu and Y. Liu, Nonphotochemical production of singlet oxygen via activation of persulfate by carbon nanotubes, Water Res., 2017, 113, $80-88$.

49 T. Q. Zhang, S. P. Chu, J. Li, L. L. Wang, R. Chen, Y. Shao, et al., Efficient Degradation of Aqueous Carbamazepine by Bismuth Oxybromide-Activated Peroxide Oxidation, Catalysts, 2017, 7(11), 315.

50 C. Cai, H. Zhang, X. Zhong and L. W. Hou, Ultrasound enhanced heterogeneous activation of peroxymonosulfate by a bimetallic Fe-Co/SBA-15 catalyst for the degradation of orange II in water, J. Hazard. Mater., 2015, 283, 70-79.

51 Y. Feng, J. H. Liu, D. L. Wu, Z. Y. Zhou, Y. Deng, T. Zhang, et al., Efficient degradation of sulfamethazine with $\mathrm{CuCo}_{2} \mathrm{O}_{4}$ spinel nanocatalysts for peroxymonosulfate activation, Chem. Eng. J., 2015, 280, 514-524.

52 Y. C. Du, W. J. Ma, P. X. Liu, B. H. Zou and J. Ma, Magnetic $\mathrm{CoFe}_{2} \mathrm{O}_{4}$ nanoparticles supported on titanate nanotubes $\left(\mathrm{CoFe}_{2} \mathrm{O}_{4} /\right.$ TNTs) as a novel heterogeneous catalyst for peroxymonosulfate activation and degradation of organic pollutants, J. Hazard. Mater., 2016, 308, 58-66.

53 Y. X. Wang, H. Q. Sun, H. M. Ang, M. O. Tade and S. B. Wang, Magnetic $\mathrm{Fe}_{3} \mathrm{O}_{4} /$ carbon sphere/cobalt composites for catalytic oxidation of phenol solutions with sulfate radicals, Chem. Eng. J., 2014, 245, 1-9. 
54 W. L. Guo, S. N. Su, C. L. Yi and Z. M. Ma, Degradation of antibiotics amoxicillin by $\mathrm{Co}_{3} \mathrm{O}_{4}$-catalyzed peroxymonosulfate system, Environ. Prog. Sustainable Energy, 2013, 32(2), 193-197.

55 C. D. Qi, X. T. Liu, C. Y. Lin, H. J. Zhang, X. Li and J. Ma, Activation of peroxymonosulfate by microwave irradiation for degradation of organic contaminants, Chem. Eng. J., 2017, 315, 201-209.

56 Y. H. Guan, J. Ma, X. C. Li, J. Y. Fang and L. W. Chen, Influence of $\mathrm{pH}$ on the Formation of Sulfate and Hydroxyl Radicals in the UV/Peroxymonosulfate System, Environ. Sci. Technol., 2011, 45(21), 9308-9314.

57 Y. J. Choi and L. S. Lee, Partitioning Behavior of Bisphenol Alternatives BPS and BPAF Compared to BPA, Environ. Sci. Technol., 2017, 51(7), 3725-3732.

58 M. M. Ahmed, S. Barbati, P. Doumenq and S. Chiron, Sulfate radical anion oxidation of diclofenac and sulfamethoxazole for water decontamination, Chem. Eng. J., 2012, 197, 440447.

59 Y. Q. Zhang, J. F. Zhang, Y. J. Xiao, V. W. C. Chang and T. T. Lim, Kinetic and mechanistic investigation of azathioprine degradation in water by $\mathrm{UV}, \mathrm{UV} / \mathrm{H}_{2} \mathrm{O}_{2}$ and $\mathrm{UV} /$ persulfate, Chem. Eng. J., 2016, 302, 526-534.

60 J. Deng, Y. J. Ge, C. Q. Tan, H. Y. Wang, Q. S. Li, S. Q. Zhou, et al., Degradation of ciprofloxacin using alpha- $\mathrm{MnO}_{2}$ activated peroxymonosulfate process: effect of water constituents, degradation intermediates and toxicity evaluation, Chem. Eng. J., 2017, 330, 1390-1400.

61 H. K. Shon, S. Vigneswaran and S. A. Snyder, Effluent Organic Matter (EfOM) in Wastewater: Constituents, Effects, and Treatment, Crit. Rev. Environ. Sci. Technol., 2006, 36(4), 327-374.

62 A. Takdastan, B. Kakavandi, M. Azizi and M. Golshan, Efficient activation of peroxymonosulfate by using ferroferric oxide supported on carbon/UV/US system: a new approach into catalytic degradation of bisphenol A, Chem. Eng. J., 2018, 331, 729-743.
63 S. D. Stan and M. A. Daeschel, 5,5-Dimethyl-2-pyrrolidone-Noxyl formation in electron spin resonance studies of electrolyzed $\mathrm{NaCl}$ solution using 5,5-dimethyl-1-pyrrolineN-oxide as a spin trapping agent, J. Agric. Food Chem., 2005, 53(12), 4906-4910.

64 M. Zalibera, P. Rapta, A. Stasko, L. Brindzova and V. Brezova, Thermal generation of stable [image omitted] spin trap adducts with super-hyperfine structure in their EPR spectra: an alternative EPR spin trapping assay for radical scavenging capacity determination in dimethylsulphoxide, Free Radical Res., 2009, 43(5), 457-469.

65 X. Chen, W. D. Oh, Z. T. Hu, Y. M. Sun, R. D. Webster, S. Z. Li, et al., Enhancing sulfacetamide degradation by peroxymonosulfate activation with $\mathrm{N}$-doped graphene produced through delicately-controlled nitrogen functionalization via tweaking thermal annealing processes, Appl. Catal., B, 2018, 225, 243-257.

66 M. Nie, Y. Yang, Z. Zhang, C. Yan, X. Wang, H. Li, et al., Degradation of chloramphenicol by thermally activated persulfate in aqueous solution, Chem. Eng. J., 2014, 246, 373-382.

67 X. J. Hou, X. P. Huang, F. L. Jia, Z. H. Ai, J. C. Zhao and L. Z. Zhang, Hydroxylamine Promoted Goethite Surface Fenton Degradation of Organic Pollutants, Environ. Sci. Technol., 2017, 51(9), 5118-5126.

68 H. Sheng, Q. Li, W. H. Ma, H. W. Ji, C. C. Chen and J. C. Zhao, Photocatalytic degradation of organic pollutants on surface anionized $\mathrm{TiO}_{2}$ : common effect of anions for high holeavailability by water, Appl. Catal., B, 2013, 138, 212-218.

69 W. D. Oh, Z. Dong, G. Ronn and T. T. Lim, Surface-active bismuth ferrite as superior peroxymonosulfate activator for aqueous sulfamethoxazole removal: performance, mechanism and quantification of sulfate radical, J. Hazard. Mater., 2017, 325, 71-81.

70 X. L. Zhang, M. B. Feng, R. J. Qu, H. Liu, L. S. Wang and Z. Y. Wang, Catalytic degradation of diethyl phthalate in aqueous solution by persulfate activated with nano-scaled magnetic $\mathrm{CuFe}_{2} \mathrm{O}_{4} / \mathrm{MWCNTs,} \mathrm{Chem.} \mathrm{Eng.} \mathrm{J.,} \mathrm{2016,} \mathrm{301,} \mathrm{1-11.}$ 